\title{
Self-harm: a strategy for survival and nodal point of change
}

\author{
Jack Nathan
}

\begin{abstract}
The author explores key issues related to psychotherapeutic work with people who self-harm. Particular attention is given to the powerful countertransference feelings that practitioners often experience in this work and the importance of managing these. Rather than maintaining a detached distance, therapists should emotionally engage with the patient's experience, creating a unique therapeutic relationship. The common patterns, functions and meanings of self-harm are discussed, with clinical vignettes that highlight the underlying dynamics of the behaviour. Self-harm is a survival stratagem, and methods for helping patients to find other ways to cope are suggested. One such is mentalisation, which can enhance the patient's capacity to think, not impulsively act. If patients learn how to assess more accurately their own and other people's states of mind, less destructive behaviours can emerge.
\end{abstract}

This article continues a brief series on self-injury begun by Leonard Fagin earlier this year (Fagin, 2006). In the remaining article Paul Gill \& Mark Broadhurst will consider repeated self-injury from the perspective of liaison psychiatry.

A clinical database study (Horrocks et al, 2003) found that as many as $80 \%$ of people who self-harmed met DSM-IV criteria for borderline personality disorder. Self-harm is a stratagem for survival, but I can offer no simple explanation of it, as each act of self-harm must be considered in the light of the patient's idiosyncratic narrative. There are, however, patterns of self-harm that individuals share. In this article I will detail the different forms that these patterns take and the way self-harm comes to constitute a unique response to a particular life situation, a response that is ultimately about the survival of the self, not its destruction.

The psychotherapeutic task begins with an understanding of these shared patterns and progresses to achieving insight into the idiosyncratic narrative particular to each patient. Vital to this task is enabling the patient to work through their relationship to selfharm and expanding their repertoire so that other, less assaultive forms of relationship can begin to emerge. This raises an interconnected issue related to the nature of the therapeutic stance that the mental health practitioner needs to adopt, and it is with this I will begin.

\section{The practitioner's therapeutic stance}

\section{Managing the countertransference}

Research has shown that patients who self-harm sometimes encounter hostile responses from practitioners in a variety of clinical settings (Warm et $a l, 2002)$. In particular, doctors and nurses working in accident and emergency departments have been reported as unsympathetic (Pembroke, 1991; Treloar \& Pinfold, 1993; Arnold, 1995). It is because of these findings that the National Institute for Health and Clinical Excellence (NICE) has issued guidance making it clear that people who self-harm 'should be treated with the same care, respect and privacy as any patient' (National Collaborating Centre for Mental Health, 2004).

This is easier said than done. Patients who selfharm pose a profound dilemma for staff. They are, by definition, both perpetrator and victim. In their role as perpetrators, they have mounted an attack on their own bodies. In these circumstances, we are all vulnerable to powerful negative countertransference reactions as self-harm is seen as the perpetration of violence. This arousal of negative responses plays into these patients' view of the environment as hostile and unhelpful. Their worlds, both internal and external, are already forbidding places.

Formerly a social work manager at London's Maudsley Hospital, Jack Nathan is now a lecturer in the Institute of Psychiatry's Health Services Research Department (PO29, David Goldberg Centre, Institute of Psychiatry, De Crespigny Park, London SE5 8AF, UK. Email: jacknathan54@hotmail.co.uk). He is also an Associate Member of the London Centre of Psychotherapy and is currently working as a consultant adult psychotherapist in the Maudsley Psychotherapy Service and Self-Harm Out-Patients Service. 
Paradoxically, when faced with intolerable and incomprehensible acts of self-assault, practitioners can be drawn into re-enactments of abuse. For example, practitioners find themselves taking a hostile, condemning stance with patients who selfharm, verbally re-enacting an abusive scenario with which the patients are all too familiar.

The alternative response is to see these individuals as victims who need to be rescued - and that might be precisely what the patient unconsciously longs for, an all-giving mother. Although less persecuting as a response, this leaves the patients infantilised, relinquished of responsibility for their selfdestructive acts, thereby maintaining the psychic status quo. Such a response also plays into the blackand-white view of the human environment as all good or all bad.

A more productive therapeutic stance requires the clinician to attune to the survivalist nature of self-harm. This raises another dilemma, a dialectical tension, because the practitioner must, as an absolute starting point, accept the patient's self-harming behaviour (Nathan, 2004). Without this, no work is possible. There is some research evidence (Koerner \& Linehan, 2000) suggesting that specific strategies such as validation and acceptance interventions may play an important role in bringing about positive behavioural change.

Yet the practitioner has also to be able to challenge the patient's self-harming behaviour. Again, without this no work is possible. This is a complex issue as there can be no hard and fast rule about the timing of such challenges. When one patient was told that she had to stop threatening suicide whenever she felt disturbed, a major row broke out between her and her practitioner. Nevertheless, the argument was resolved and therapy progressed (McLean \& Nathan, 2006). The key point in this successful limit-setting is that it was based on the patient's attachment to the practitioner, built up over 2 years. Relationship therefore is also of primary importance in the work.

\section{Teaching through relationship: use of the patient's adult self}

Development takes place primarily in the context of an attachment relationship. In a review of the outcome literature for psychotherapy, Lambert \& Barley (2001) found that by far the largest positive factor was the therapeutic relationship. The Department of Health's (2001) guidelines on treatment choice stresses that 'effectiveness of all types of therapy depends on the patient and the therapist forming a good working relationship' (my emphasis). This finding is accorded the greatest research-based weighting.
There is also an increasing body of evidence (see Bateman \& Fonagy, 2004) from child development studies suggestive of the notion that the capacity to evolve reflective thinking takes place only within the context of a close interpersonal relationship. This research is beginning to make it clear that, for treatment of personality disorder to be effective, the patient must have an attachment to the therapist. The intensity of the attachment brings into the treatment setting what I call the patient's relationship template. This template, or what Bowlby (1973) called the individual's 'internal working model', inevitably arises in the treatment. In other words, patients bring into the therapeutic setting their ways of thinking, feeling and, worryingly, behaving. How could they not do so? A massive dynamic tension emerges (or sometimes erupts) when the most sensitive areas of the patient's life are explored.

To deal with these inevitable dynamic tensions, the psychodynamic practitioner adopts a collaborative approach by engaging the patient's adult self in treatment. This approach brings practitioners closer to cognitive-behavioural therapy and what Bateman \& Fonagy (2004) have called mentalisation-based treatment. Their methodology has moved away from the requirements for technical neutrality and transference interpretation associated with the more classic psychoanalytic form.

\section{The use of self: the clinician's active emotional engagement}

When undertaking this work, the skill, experience, attitudes and interpersonal ability of the practitioner need tobe taken into account. Studies have suggested that therapists who demonstrate characteristics such as competence and flexibility can positively influence outcome (Shaw et al, 1999). It is likely that the interpersonal skills of the therapist may be a determining factor in patient retention and outcome. In the terms that I am using here, what is required of the practitioner is a vigilant monitoring of the interpersonal dynamic tension. It must hold the dialectic between creating an atmosphere of tolerance in which the therapist can deal with the sheer awfulness of what the patient is revealing and their own engagement with that experience. Under such psychic pressures, it is even more necessary to maintain professional boundaries. Psychotherapists should never be friends with their patients. And yet to foster change and model tolerance and flexibility in a relationship, active emotional engagement is essential.

As suggested above, this approach lays stress on using the patient's adult self in the service of creating an interpersonal dynamic with the 
therapist; one that brings into the open the patient's relationship template. For the practitioner this means engaging with their own emotions in the hothouse of development, here-and-now atmosphere of the session. The objective therapist, if ever one existed, has to struggle with their own subjectivity. Bateman (1998) writes that patients with borderline personality disorder may need to experience a therapist who can tolerate becoming 'entangled with their (the patient's) terror' (p. 23, my emphasis). The shared sense of reality is affectively as well as cognitively experienced in the moment. The relationship template comes alive in the consulting room.

In the best of circumstances, when neither the patient nor the practitioner is too tormented by the experience and the adult thinking self of both has survived, an opening exists in which a new initiative is possible. It is one freed from the imperative to constantly replay the patient's pathological relationship template (Stern et al, 1998). In self-harm, this template invariably takes the form of basic distrust of the object world and / or profound hatred of the self. In other words, the usually pathological relationship template is shifted and there is space for a more benign template to develop, helping to create what Alexander \& French (1946) described as 'a corrective emotional experience'.

For the therapist, an essential requirement emerging from such an intense emotional engagement is the belief in their own benign impulses. From this perspective, psychotherapists have moved beyond the view of the Freudian practitioner presenting a mirror for reflection. Patients who self-harm require a real relationship. By this I mean one in which the practitioner brings the best of themselves, their benign impulses, to the therapeutic encounter. As McLean \& Nathan (2006) make clear, this also includes their benign authority where the clinician is prepared to make judgements about the patient's behaviour. Making judgements is not to be confused with being judgemental, which implies condemnation, superiority and rejection of the patient.

These benign impulses cannot be counterfeited, as they will also be seen through by the patient. This is perhaps why Bateman \& Tyrer (2004a) make the point that not everyone can treat patients with personality disorders. What the clinician requires is a capacity to believe that, whatever their own shortcomings, they are ultimately acting in the interest of their patients. In more graphic terms, the psychotherapist's good intentions outweigh their malign or even sadistic ones. This struggle with their own complex conflicts, including sometimes hatred of what their patients put them through, is itself therapeutic and represents a modelling of an alternative mode of relating. However awful they may feel, they do not turn to self-harm, suicide or violence for resolution. The patient is always observing this process, where the practitioner is struggling to manage their own ambivalences. For people who self-harm this is one key marker of what they cannot manage.

\section{The personal as professional}

Furthermore, therapists must relate to the patient in a way the patient experiences as specific and unique to their relationship, as this implies that they are engaging with the patient's 'personal signature' (Stern et al, 1998) and that it is one worthy of emotional engagement. It is therefore not enough to be a technically competent practitioner. For patients with personality disorders this is tantamount to a subtle form of abandonment and thereby rejection of a self that is already too depleted of any sense of self-worth.

Perhaps, above all, the clinician has to sustain a sense of hope in the possibilities of life. One patient, Susan, ${ }^{1}$ once gave me a tiny violet, letting me know that I had to hold it as she would destroy its 'fragile beauty'. She was, I think, referring to this hope residing in me. As with many patients, Susan suffers the reverse. She is filled with despair, fear of her own self-destructiveness and hopelessness. In psychoanalytic terms, Susan has projected all her hope for a better life, or any life at all, into the therapist. Hers is a bleak life, tempered perhaps only by moments of relief through self-harm. This creates another dialectical conflict. The practitioner has to hold the tension of representing hope without being driven to represent an idealised figure who will resolve all of the patient's problems.

We must not, however, underestimate the therapeutic value of this kind of projection. After I asked Susan to reduce her daily acts of blood-letting to every other day, she wrote:

'Something in Jack still has hope and I did feel this walking home... I don't know but something makes me want to try for him not for me' (patient's emphasis).

I think this patient is consciously communicating that the hope resides in me; she has no direct experience of it. But she does have an experience of me that she carries with her outside of the session when walking home. If she is to change, she has to 'borrow' hope from me. This will enable her to try, for me, to reduce her acts of blood-letting. Not surprisingly, these episodes have continued to be a feature of Susan's life. Perhaps more surprisingly,

1. The patients' stories given here are true and are told with their permission. Names have been changed to help protect individuals' identity. 


\section{Box 1 The practitioner's therapeutic stance}

In treating self-harm the therapist must be able to:

- hold a dialectical tension

- both accept and challenge self-harm

- understand the patient as both victim and perpetrator of self-harm

- use their own personality to emotionally engage with the patient

- tolerate attacks on their professional competence

- recognise their own limits and not take all that patients dish out

- encourage the patient's adult self as collaborator in the treatment

she has managed to significantly reduce her acts of blood-letting so she no longer needs the hospital transfusions she required in the past.

Box 1 summarises key requirements of practitioners who treat self-harm.

\section{The patient's stance: meanings and functions of self-harm}

As mentioned above, shared patterns of self-harm are evident (Box 2), although each act has meaning specific to each individual.

\section{Self-harm as a relationship}

One way the practitioner can begin to tolerate the kind of disturbance aroused by patients who selfharm is to work with them to make sense of the idiosyncratic narrative that has produced their behaviour.

\section{Box 2 Some meanings and functions of self- harm}

- A way of surviving a relationship

- A form of communication

- An expression of rage

- A form of punishment of self and others

- A defence against murderous rage

- A way of dissociating

- A way of feeling 'real'

- A defence against 'bad' sexual affect
I heard a patient letting me know that for her, selfharm was a way of surviving: 'It is what I live for, it keeps me alive'. Here is a clear statement of just how important it is not to confuse self-harm with suicide. This helped to tailor my thinking as I understood how vital it was not to orient the treatment towards premature cessation of her acts of self-harm.

Implied in this patient's view is a fundamental, hidden dynamic. For many people, self-harm is a relationship. Susan told me how she had survived her best friend's emigration. At first, she sobbed, becoming increasingly alarmed that the pain would never go away. After some hours, she made the decision to self-harm and soon felt 'fine', i.e. she felt nothing about her friend's abandonment of her. I asked Susan to write about the pros of a self-harming relationship and the cons of a human relationship.

Her writing was remarkably illustrative of Susan's state of mind, one dominated by terror of people who leave her feeling exposed, ashamed and inadequate, with little to offer - only 'becoming too dependent on their existence in my life'. And, of course, her friend's departure had reinforced her belief in the self-harming relationship, which she described in glowing terms as one that offers her security, comfort, safety. She wrote of a relationship that helps her cope, enabling her to be more detached, that makes no demands on her and that she can trust - unlike her friend, this relationship would never let her down.

The implications of thinking of self-harm as a relationship are manifold. Another patient, Anne, whose ex-husband was now starting a family with his new partner whereas she and her three daughters were about to be evicted, was furious at the thought of stopping self-harming. She powerfully lay claim to her wish to self-harm: 'I've had my husband taken away from me, all I earn is taken to pay my debts, I'm about to have my house re-possessed. Self-harm is the one thing that can't be taken away; it's mine, it's for me'.

As if to convey the double meaning that self-harm was for her and a relationship, Anne went on to say that she had 'fixed a date' to self-harm the following week. Clearly, the practitioner has to recognise that challenging self-harming behaviour requires mourning the loss of a profound relationship that has perhaps literally kept the patient alive. With one patient, Dawn, a ritualised ending was elaborated. This began with putting words to her self-experience in the session, for example 'ugly, fat bitch'. Next, she wrote these reflections in her diary, while she continued to self-harm. Then she suggested writing these words on to her body in place of self-harming. After that, she re-transferred these self-ideas back into her diary, without having to undertake further acts of cutting. 


\section{Self-harm as 'negative liberation'}

The patients' stories that I have mentioned here highlight the importance of self-harm as an experience in which the patient can feel in control. Clare, who inserted needles into her ears, communicated something of her excitement when she discovered self-harm: 'It was totally mine and the pain belonged to my control'. She went on to suggest that self-harm is an act of 'negative liberation', usually from an experience of self that is tortured beyond meaning or comprehension.

Patients are often unable to get past an experience of 'feeling bad', sometimes accompanied by bodily sensations that are described as 'weird', 'blank' or 'unreal'. The psychoanalyst Bion (1967) suggests that such individuals are unable to give meaning to somatic experience; they might have no idea that 'butterflies in the stomach' are a sensation for which we might use the word worry. They are therefore less able to translate the language of the body into a language of a psyche apprehending a range of complex emotions. Theirs is an experience that is raw and sometimes bizarrely psychotic, leaving them overwhelmed, out of control and terrified. It is not surprising that, in these circumstances, they resort to self-harm. One patient, Charlotte, described selfharm in terms of being able to turn a formless, nameless, tormenting experience into something she could visualise. By cutting, she was able to be witness to her own pain, writ large and concretely on her abdomen. Charlotte gave meaning through the pain of self-harm to an experience that had previously lacked meaning. Paradoxically, it made her feel real.

For other patients, the intention is to achieve the opposite; they feel all too real. By self-harming they want to create a space to feel 'unreal', numb and dissociated. Most strikingly, in their relationships with people these individuals are overwhelmed by a consciousness of being tormented. Anne could not bear losing her husband to another woman. She felt tortured by the experience. Clare was overwhelmed by an internal, ever-hostile mother. There was no alternative good maternal voice to counter this relentless hell. Clare described self-harm as an act of 'erasure, wiping the slate clean'. She was describing an illegible, alien script that dominated her being. Self-harm was, in her own words, 'an act of repossession' of her self, a way of creating a space that was hers, untrammelled by what Bateman \& Fonagy (2004: p. 89) refer to as 'an alien experience within the self'.

\section{Self-harm as communication}

Anne gave an account of a time when her marital relationship was already very shaky. She and her husband had serious financial problems and she was suffering from severe post-natal depression. During a discussion one evening, her husband fell asleep. Anne was furious and threw cold water over him. He was so shocked that he 'reacted as if I was wanting to stab him'. The following night he mockingly asked whether she was planning to throw a bucket of hot water over him. Anne decided that was it, she stabbed herself repeatedly all over her arm. Anne remembers the experience as a desperate attempt to influence her husband, essentially to be more caring towards her, and to communicate her level of despair.

\section{Self-harm as an expression of rage}

Clearly there were other dynamics at work in Anne's situation, including her need to protect herself as well as her husband from the murderous rage she claimed was only his concern.

Individuals who self-harm are often unable to cope with their anger or rage. One patient, Joyce, described the following 'trivial' example. Her partner, Tony, came home from work and did not say 'hello' to her. Within seconds, Joyce found herself in the bathroom punching her face, causing severe bruising. There was no question of her being able to talk to Tony about being upset or angry that he had not acknowledged her.

\section{Self-harm as punishment of self and others}

One consequence of Joyce's self-violence was that it left Tony acutely embarrassed when he went out with her, as he feared that people would think him a 'wife batterer'. This was probably Anne's unconscious intention.

Harry, a patient who had a self-harming relationship lasting nearly 60 years, returned to therapy after a break only to announce that he had not gone to his son's for Christmas dinner as planned. He explained that this was because his ex-wife had suggested to him that his daughter had taken his plan to join his son for the day to mean that he loved her less and his son more. Harry could not cope with the dilemma, made excuses about being ill and subsequently self-harmed for the first time in months. Having been in treatment for over 2 years, Harry accepted my interpretation that he was fed up with his feuding family and was punishing them. By not joining either of his children for Christmas dinner and by self-harming, Harry was not only punishing his family, but also punishing himself for his 'bad' behaviour. 
Here we see the vicious circle of self-harm at work. Like many patients, Harry self-harms because he is 'bad' and he is 'bad' because he self-harms. 'Being bad' is a key experience of individuals who selfharm. Descriptions of themselves as 'bad', 'ugly', 'dirty bitch', 'disgusting monster' and so on are common. Tina, a young woman who had been severely sexually abused by a number of members of her family, described herself with a venomous self-hatred as 'pathetic and weak', thought she deserved to be abused and in effect was re-enacting her abuse experiences in self-harm. Another patient hated her 'dirty' sexuality and whenever aroused 'cleansed herself' by inserting a knitting needle into her vagina and anus: the pain put a stop to any sexual pleasure.

\section{The presence of the 'bad object' (the absence of the 'good')}

What all these individuals have in common is an absence of a 'good internal object' that can help contain their experience. The model for this is the mother-infant relationship, in which the mother (or carer) uses her understanding to help the infant with their anxieties (e.g. a crying baby may be hungry). As these experiences are repeated over and over again, the infant comes to internalise this relationship. This benign relationship template is carried within, helping to form a secure base that acts as a model for a self that is able, on the whole and through supportive relationships, to regulate affect (see Bion, 1967; Segal, 1981). Herein we see the development of a relationship template that provides mental stability. These ideas have been empirically corroborated by Fonagy et al (1997). They assessed parents before the birth of their child and found that demonstrating a high capacity to reflect predicted a secure attachment relationship in the child.

If these experiences are absent, a relationship template suffused with a persecutory and terrifying script takes a stranglehold on the individual's mental life. Theirs is an 'invalidating' environment (Linehan, 1993). Instead of finding a human relationship to contain overwhelming anxieties, the individual may turn to what is essentially a perverse relationship based on self-harm.

The absence of the benign relationship template leaves patients feeling, as one put it, 'unequipped'. There is a sense that something in their capacity to regulate experience is missing. Sometimes a relatively trivial experience such as a passer-by barging past without apologising can trigger an enormous and on-going rage. This can lead to acts of self-harm or, if the individual is particularly paranoid, to violence, as there is little sense of a self worthy of attention and respect.

\section{Treatment orientation}

\section{The dialectical tension}

As suggested above the clinician has the complex task of having to orient themselves to a stance that is both accepting and challenging of self-harm. This dialectical tension has to be held. Initially, taking a non-condemning, accepting stance facilitates therapeutic engagement. However, the practitioner has to hold the tension that includes of the challenge, whether or not it is explicit at the beginning. After all, the patient knows this to be the case at some level, otherwise they would not be seeing a therapist. Moreover, this form of dialectical tension is one with which patients themselves are constantly having to grapple. Writing in bold in a diary of her experience Dawn could claim, 'no one cares about you bitch, I h8 me' (patient's syntax), and on the next line, 'please love me, please care about me'. She wanted her crushing self-experience to be challenged through being loved and accepted.

\section{Facilitating mentalisation}

The clinician has to help the patient to expand their ability to create a meaningful narrative from the chaos of this extreme of self-hatred and longing. People who self-harm have a deficit in their capacity to think about their experiences. Life is action. A perceived stare is psychically equivalent to a physical assault. Self-harm, a physical act par excellence, might be their only way to express psychic pain. Treatment based on mentalisation (Bateman \& Fonagy, 2004) specifically attends to helping people with borderline personality disorder to kick-start a process of mental functioning that addresses such experience. I once made what I thought was a rather obvious comment to Joyce about her anger, after she had again punched herself in the face. She was horrified. She had never thought of herself as an angry person.

The focus of treatment is to help patients such as Joyce to create a meaningful narrative out of the raw material of repetitive, stereotyped experiences.

\section{An example}

Joyce's typical reaction can be broken down into two steps.

Step 1 Joyce is confronted by a tormenting environmental insult, experienced as an assaultive action against her self - her husband Tony returns home from work and does not say 'hello'.

Step 2 There follows a 'nameless', inexplicable internal experience that results in an explosive, violent assaultive reaction 
- punching herself in the face. There is an absence of any thought like 'I'm angry he did not acknowledge me'. Instead, Joyce 'explodes' into a counteraction.

To make meaning of her experience Joyce needs to create a stage between steps 1 and 2 where a thought about her anger with Tony, or even realising she has anger inside her, is developed.

The ability to contain affects, which is to say not simply to act on them, relies in part on the ability to read one's own and others' mental states more accurately. What I call 'paranoid' or 'simple' mentalisation is part of the human condition. We can all feel 'got at', responding without thought but with action. 'Complex' mentalisation means being able to read experiences of the environment and of the self beyond attacks on the depleted self. In Joyce's case, this eventually took poetic form. Looking back on that experience she wrote,

'Something so trivial left me cold,

You went out of the room to be alone,

Rejection, pain, hate,

Slap, punch without thought' [my emphasis].

Joyce demonstrates a developing capacity to imaginatively read her husband's as well as her own mental state that is beyond the psychologically primitive experience of having been ignored. She could see that Tony needed to be alone for a while after work. Simple mentalisation was transformed into complex mentalisation that took account of her husband's as well as her own experience.

The capacity to mentalise also creates an ability to begin to reflect on the kinds of experiences one can evoke in others. Christine, a traumatised, emotionally silent patient who worked as a nurse, once gave an account of trying for hours to persuade someone on her hospital ward to take a bowel preparation medication before an operation. In her diary, Christine wrote: 'I can really sympathise with Jack having me sat in front of him not doing what needs to be done. It's so frustrating'.

\section{The dialectics of treatment}

Bateman \& Fonagy's (1999; 2001) research into mentalisation-based treatment has shown that, by enhancing the patient's capacity to mentalise, the need to resort to self-harming decreases. They believe that creating an emotionally meaningful narrative requires encouraging the patient to make this meaning (Bateman \& Fonagy, 2004). A key task for the clinician is to ask pertinent clarificatory questions. If a patient has recently self-harmed, emphasis is placed on helping them think about what was going on at the time, for example, what pressures they were under, what might have made them angry or upset, what they were worried about. The practitioner provides the therapeutic framework through demonstrating that they are thinking about and showing an interest in the patient. However, it is for the patient to make the meaningful links so that they come to recognise and manage their feelings.

Bateman \& Fonagy (2004) are raising fundamental questions about the use of the more classically framed psychoanalytic interpretation. Many people who self-harm simply cannot tolerate that more detached, interpretive stance. If they appear to do so, the authors suggest that amounts to a form of intellectualising referred to as 'pretend mode' functioning. Meaningful work appears to be taking place, but in fact it does not touch the emotional core of the patient's experience. Although they are right in pointing to such dangers, Bateman \& Fonagy underestimate what I think of as the dialects of a treatment that includes a human relationship in which the practitioner significantly contributes to the treatment process. It is not only for the patient to make meaning of their experience: the clinician must do so as well. This is not surprising, as the grammar and language of affect are being developed. This is hardly likely to happen in therapy, as in life, without the 'teaching' provided by the therapeutic practitioner. Through this process, the patient is helped to go from a state of illiteracy to one of cognitive and emotional literacy.

This can take a number of different forms. For Charlotte, her discovery that she needed to visualise her pain by cutting was an important milestone in her treatment. Through the enhancement of her cognitive and emotional vocabulary Charlotte paradoxically began to self-harm less often. With Joyce, she was able to articulate her sense of rage at being ignored by her husband and think through his, as well as her own, experience of that situation. This was made possible by my having provided a thought, that she had anger inside her. This helped to contain that experience and enabled her to think about its ramifications. Winnicott (1971) summarises the nature of this experience when he writes 'Psychotherapy takes place in the overlap of two areas of
playing, that of the patient and that of the therapist' (p. 44;
Winnicott's emphasis).

For someone who self-harms, creating a meaningful narrative comes out of the work (or 'play') of both participants in the treatment.

I will end with an example. Charlotte once came to a session in a state of depressed exhaustion. She was furious with herself for being so sleepy. I suggested that her response to being depressed and exhausted was to attack a self that was already weak. There was an absence of any kind of sympathy for her 
vulnerable, needy self. She was both the abuser and the abused. She went on to tell me that she was having dreams in which she was killing babies. I interpreted that she was letting me know that her violence against her infantile self was now following her into her dreams. Charlotte, a classics student, made an association to a Greek myth in which a man follows his love into her dream in order to get her out of a sleep state. This had a containing effect for Charlotte, as she went from being soporific to engaged and enthusiastic. Once more she felt that her raw, 'shapeless' experience had been transformed and could be pictorially visualised and understood. Getting to this point required both of us working together.

\section{Conclusions}

Working with patients who self-harm is complex and emotionally demanding (Box 3). This is not only because of the demands made of the practitioner by the patient, but also specifically because of the clinician's need to manage a variety of dialectical tensions. These include maintaining a position that both accepts and challenges the patient, and adopting an active emotional engagement while at the same time managing a stance that has focus and boundaries.

In the UK, we have reached a moment when personality disorder is 'no longer a diagnosis of exclusion' (Department of Health, 2003). Simultaneously, a growing body of evidence has emerged from both the psychodynamic and the cognitive therapy schools suggesting that the psychological therapies do offer worthwhile treatments for selfharm (Perry et al, 1999; Leichsenring \& Leibing, 2003; Bateman \& Tyrer, 2004b). Although Bateman \& Tyrer (2004b) tentatively suggest that the evidence base tends towards psychodynamic therapy, they also make it clear that we need to continue to develop effective treatments. This article is a contribution to that evolving process.

\section{Declaration of interest}

None.

\section{Refer ences}

Alexander, F. \& French, T. M. (1946) Psychoanalytic Therapy. New York: Ronald Press.

Arnold, L. (1995) Women and Self-injury - A Survey of 76 Women. Bristol: Bristol Crisis Service for Women.

Bateman, A. (1998) Thick- and thin-skinned organisations and enactments in borderline and narcissistic disorders. International Journal of Psychoanalysis, 79, 13-25.

Bateman, A. W. \& Fonagy, P. (1999) The effectiveness of partial hospitalisation in the treatment of borderline personality
Box 3 Requirements and features of therapeutic work with patients who self-harm

- The work should be intensive and longterm (weekly sessions for at least 18 months to 2 years or more)

- Active emotional engagement of the practitioner

- Mistakes and enactments of the patient's problems will inevitably occur

- The therapeutic environment should provide an opportunity to reflect on these mistakes and enactments (even when they are the practitioner's)

- A narrative construction should emerge (of the 'Oh, I see this is what happens when I feel attacked/rejected/bad, just as it did the last time' variety)

- This construction will be a product of both patient and clinician

- Experience of working on these repeated dynamics will help the formation of an enhanced reflective capacity (i.e. enabling complex mentalisation). This will improve the patient's ability to think rather than destructively act, or to act in a way that is more self-protective or less self-destructive (harm minimisation)

disorder. A randomised controlled trial. American Journal of Psychiatry, 156, 1563-1569.

Bateman, A. W. \& Fonagy, P. (2001) Treatment of borderline personality disorder with psychoanalytically oriented partial hospitalisation. An 18-month follow-up. American Journal of Psychiatry, 158, 36-42.

Bateman, A. W. \& Fonagy, P. (2004) Psychotherapy for Borderline Personality Disorder: Mentalisation-based Treatment. Oxford: Oxford University Press.

Bateman, A. \& Tyrer, P. (2004a) Services for personality disorder: organisation for inclusion. Advances in Psychiatric Treatment, 10, 425-433.

Bateman, A. W. \& Tyrer, P. (2004b) Psychological treatment for personality disorders. Advances in Psychiatric Treatment, 10, 378-388.

Bion, W. R. (1967) Second Thoughts. London: Heinemann

Bowlby, J. (1973) Attachment and Loss. Vol. 2: Separation. London: Hogarth Press \& Institute of Psychoanalysis.

Department of Health (2001) Treatment Choice in Psychological Therapies and Counselling: Evidence Based Clinical Practice Guideline. London: Department of Health.

Department of Health (2003) Personality Disorder: No Longer a Diagnosis of Exclusion. London: Department of Health.

Fagin, L. (2006) Repeated self-injury: perspectives from general psychiatry. Advances in Psychiatric Treatment, 12, 193-201.

Fonagy, P., Steele, M., Steele, H., et al (1997) Reflective-Functioning Manual for Application to Adult Attachment Interviews. London: University College London.

Horrocks, J., Price, S., House, A., et al (2003) Self-injury attendances in the accident and emergency department. Clinical database study. British Journal of Psychiatry, 183, 34-39.

Koerner, K. \& Linehan, M. M. (2000) Research in dialectical behaviour therapy for patients with borderline personality disorder. Psychiatric Clinics of North America, 23, 151-167. 
Lambert, M. J. \& Barley, D. E. (2001) Research summary on the therapeutic relationship and psychotherapy outcome. Psychotherapy, 80, 1075-1091.

Leichsenring, F. \& Leibing, E. (2003) The effectiveness of psychodynamic therapy and cognitive behaviour therapy in the treatment of personality disorders. A meta-analysis. American Journal of Psychiatry, 160, 1223-1232.

Linehan, M. (1993) Cognitive Behavioral Treatment of Borderline Personality Disorder. New York: Guilford Press.

McLean, D. \& Nathan, J. (2006) Limit setting and the use of benign authority. British Journal of Psychotherapy, in press.

Nathan, J. (2004) In-depth work with patients who self-harm: doing the impossible. Psychoanalytic Psychotherapy, 18, 167181.

National Collaborating Centre for Mental Health (2004) Selfharm: The Short-term Physical and Psychological Management and Secondary Prevention of Self-harm in Primary and Secondary Care (CG16). Leicester: British Psychological Society.

Pembroke, L. (1991) Visits to A and E. Nursing Times, 87(49), 30-32.

Perry, J. C., Banon, E. \& Ianni, F. (1999) Effectiveness of psychotherapy for personality disorders. American Journal of Psychiatry, 156, 1312-1321.

Segal, H. (1981) The Work of Hanna Segal. New York: Jason Aronson.

Shaw, B. F., Elkin, I., Yamaguchi, J., et al (1999) Therapist competence ratings in relation to clinical outcome in cognitive therapy of depression. Journal of Consulting and Clinical Psychology, 67, 837-846.

Stern, D. N., Sander, L. W., Nahum, J. P., et al (1998) Noninterpretive mechanisms in psychoanalytic therapy. The 'something more' than interpretation. International Journal of Psychoanalysis, 79, 903-921.

Treloar, A. J. \& Pinfold, T. J. (1993) Deliberate self-harm. An assessment of patients' attitudes to the care they receive. Crisis, 14, 83-89.

Warm, A., Murray, C. \& Fox, J. (2002) Who helps? Supporting people who self-harm. Journal of Mental Health, 11, 121-130.

Winnicott, D. W. (1971) Playing and Reality. London: Tavistock Press.

\section{MCQS}

1 Dealing with countertransference responses to patients who self-harm requires of psychotherapists:

a that they remain open to powerful emotional engagements

b a capacity to reflect on the experience

c an infinite amount of patience

$\mathrm{d}$ a tolerance of all that the patient throws at them

e a capacity to use their own personality in the work.
2 With these patients it is important to:

a take a no-nonsense approach, to avoid collusion

b set appropriate limits

c create a tolerant environment

$\mathrm{d}$ be accepting of the patient

e be challenging of the patient.

3 Self-harm needs to be thought of as:

a a meaningless act

b a creative act

c a destructive act

d a form of survival

e a relationship.

4 Mentalisation-based treatment:

a comes out of the psychoanalytic tradition

$\mathrm{b}$ requires analysis sessions five times a week

c is an attachment-based treatment

$\mathrm{d}$ encourages the patient to trust their instincts

e enhances the patient's capacity to think about their own and other people's experiences.

5 With patients who self-harm the therapeutic tasks include:

a allowing the development of the patient's relationship template

b encouraging the use of the adult self

c being judgemental

$d$ being actively emotionally engaged

e having to sustain hope. 